\title{
Dehydrogenation of dimethylamine-borane mediated by Group 1 pincer complexes ${ }^{\ddagger}$
}

Roberto Nolla-Saltiel, Ana M. Geer, William Lewis, Alexander J. Blake and Deborah L. Kays*

School of Chemistry, University of Nottingham, University Park, Nottingham, NG7 2RD, UK. Email: Deborah.Kays@nottingham.ac.uk

‡ Dedicated to Prof. Philip Power on the occasion of his $65^{\text {th }}$ birthday

Electronic Supplementary Information (ESI) available: full experimental details, crystallographic data and CIF files for 1-4 and 8a. CCDC-1581977-1581982. For ESI and crystallographic data in CIF or other electronic format see DOI: 10.1039/c7cc08385h

\begin{abstract}
Group 1 salts containing carbazolido NNN pincer ligands are precatalysts for the dehydrogenation of $\mathrm{Me}_{2} \mathrm{NH} \cdot \mathrm{BH}_{3}$. NMR monitoring and DOSY studies show a heavy dependence on the metal and solvent, allowing in some cases selective formation of dehydrogenation products consistent with hydrogen liberation.
\end{abstract}

\section{Introduction}

The catalytic dehydrocoupling/dehydrogenation of ammonia borane $\left(\mathrm{H}_{3} \mathrm{~N} \cdot \mathrm{BH}_{3}\right)$ and related amine-boranes is the subject of increasing research interest ${ }^{1}$ due to the use of this process in applications such as hydrogen storage, ${ }^{2}$ hydrogen transfer reagents ${ }^{3}$ and BN-based ceramics and polymers. ${ }^{4}$ While it is possible to effect thermal release of hydrogen from ammonia borane or amine-boranes using high temperatures, the electronegativity difference between nitrogen and boron also permits the release of hydrogen mediated by a catalyst. Although there are a number of main group stoichiometric or catalytic dehydrogenation reactions using complexes featuring the Group $2^{5}$ or p-block ${ }^{6}$ elements, precatalysts based on Group 1 complexes remain largely unexplored in this, ${ }^{7,8}$ or other related catalysis. ${ }^{9}$ The high natural abundance of the three lightest congeners of Group $1(\mathrm{Li}, \mathrm{Na}, \mathrm{K})$ and their lack of participation in Schlenk-type equilibria, ${ }^{8}$ makes them ideal candidates for use as well defined precatalysts for dehydrogenation reactions.

An issue with the use of Group 1 precatalysts for amine-borane dehydrogenation has been recently highlighted by the groups of Hill and Mulvey, where the active catalysts can form insoluble metal hydride aggregates which can hinder catalytic processes. ${ }^{7,} 8$ Pincer ligands are attractive for the design of robust and effective catalysts, as they provide increased thermal stability through tridentate coordination and rigid steric protection, preventing aggregation at the metal centre whilst allowing the approach of small molecules for reaction. ${ }^{10}$ 


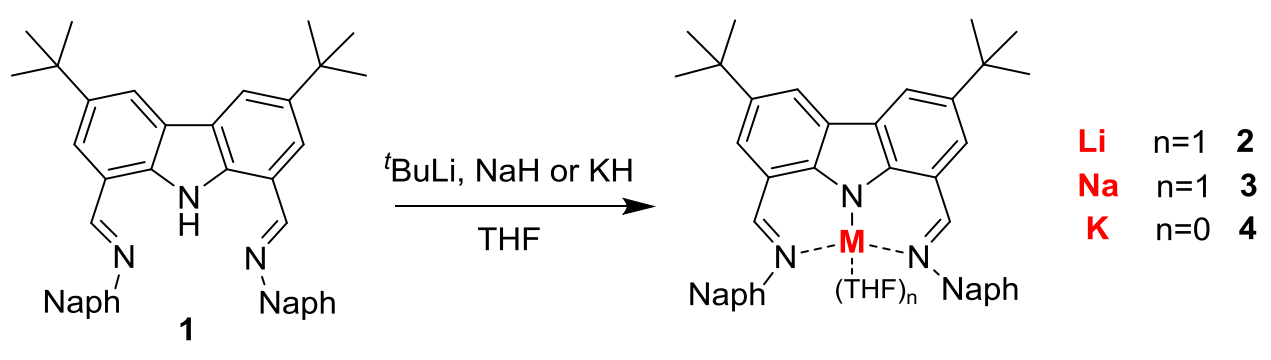

Scheme 1. Synthesis and structure of the Group 1 complexes (2-4). Reaction conditions: 2 ($78{ }^{\circ} \mathrm{C} \rightarrow \mathrm{rt}, 1$ h.), 3 ( $0{ }^{\circ} \mathrm{C} \rightarrow \mathrm{rt}, 16$ h.), 4 ( $0^{\circ} \mathrm{C} \rightarrow \mathrm{rt}, 3$ h.) Naph = 1-Naphthyl

We have recently described the use of sterically demanding carbazolido ligands in the stabilisation of low-coordinate, monomeric main group complexes; ${ }^{11}, 12$ these rigid ligands offer a strong $\sigma$-donor functionality, and the incorporation of bulky substituents in the 1- and 8-positions offers a superior degree of protection around the central carbazolido-nitrogen compared to other sterically demanding ligands such as $m$-terphenyls. ${ }^{12}$ Carbazolido NNN pincer ligands offer tuneable protection which can be facilitated through the flanking substituents, which have shown to be essential to form complexes featuring unsaturated and/or highly reactive metal centres, and such transition-metal complexes have been investigated for the catalysis of processes such as methanol carbonylation, ${ }^{13}$ Nozaki-Hiyama allylations, ${ }^{14}$ enantioselective asymmetric epoxidations ${ }^{15}$ and hydrogenation of alkanes and alkenes. ${ }^{16}$

Herein we describe the formation of three Group 1 NNN carbazolido pincer complexes which are precatalysts for the dehydrogenation of dimethylamine-borane, the metal playing a vital role in the outcome of the reaction and the overall products observed. Proligand 1,8dinaphthylimino-3,6-di(tert-butyl)-9H-carbazole ( $\left.\mathrm{Naph}_{2} \mathrm{CarbH}, 1\right)$ was synthesised in good yield through the acid-catalysed reaction between 1,8-diformylcarbazole and two equivalents of 1-naphthylamine. ${ }^{17}$ Crystals of 1 suitable for X-ray diffraction were grown from slow evaporation of a hexane/ethyl acetate solution (Fig. S14), and show that the flanking naphthyl groups lie parallel in an anti-fashion and in close proximity [3.703(12) $\AA$ ] due to $\pi$ - $\pi$ stacking.

Deprotonation of 1 using ${ }^{t} \mathrm{BuLi}$ or $\mathrm{MH}(\mathrm{M}=\mathrm{Na}, \mathrm{K})$ in THF affords $\mathrm{Naph}_{2}$ carbM(thf) $[\mathrm{M}=\mathrm{Li}(2), \mathrm{Na}(3)]$ and $\left[\mathrm{Naph}_{2} \mathrm{CarbK}_{2}\right.$ (4), as bright orange-red solids which rapidly decompose in contact with air and/or moisture (Scheme 1). Pure samples of 2-4 are readily isolated from THF at room temperature $(\mathrm{rt})$ with moderate yields of isolated crystalline material $(2,45 \% ; 3,36 \% ; 4,42 \%)$, and have been fully characterised. Compounds 2-4 are readily soluble in solvents such as toluene and benzene, and NMR measurements indicate only one species in solution. The increase in ionic radii can be followed using the most distal protons on the naphthyl substituents in $\mathbf{2}$ and $\mathbf{3}$ in the ${ }^{1} \mathrm{H}$ NMR spectrum. Asymmetry is observed in the aforementioned resonances $\left(\mathrm{H}^{\prime}{ }^{\prime}-\mathrm{H} 8^{\prime}\right.$ of naphthyl) for $\mathbf{4}$, and suggests a greater degree of interaction between the metal centre and one of the flanking groups (Fig. S7); ${ }^{18}$ the increasing alkali metal ionic radius favouring the adoption of a higher hapticity binding motif. This inclines to be true in cases in which the flanking groups are bulky and have little to no possibility of accommodating the metal centre, where the classical $\sigma$-bond conformation gets replaced by a multi-hapto $\pi$-bonded mode. ${ }^{12,19}$ When ${ }^{n} \mathrm{BuLi}$ is used in the synthesis of 2, considerable mono-alkylation of a flanking aldiminic group could be observed 
(>50\%; Fig. S16); indicative of the predisposition of the ligand to be functionalised by strong nucleophiles.

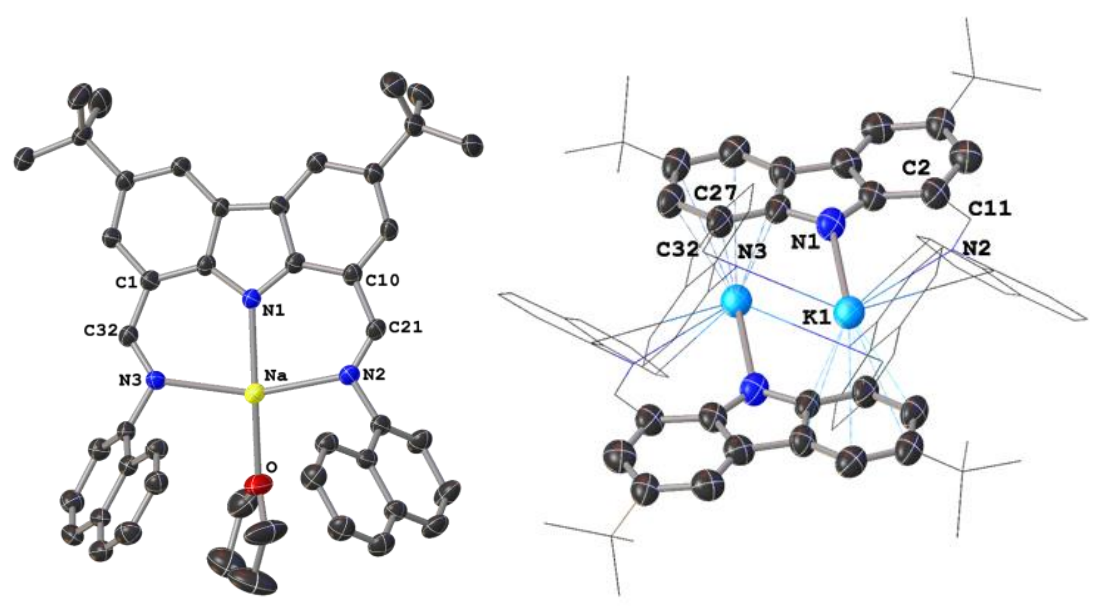

Fig. 1. Molecular structure of 3 and 4 with anisotropic displacement ellipsoids set at $50 \%$ probability. Hydrogen atoms have been omitted for clarity. Selected bond lengths $(\AA)$ and angles $\left({ }^{\circ}\right)$ for 3 and 4; 3: $\mathrm{Na}(1)-\mathrm{N}(1)$ 2.287(3); $\mathrm{Na}(1)-\mathrm{N}(2) 2.398(3) ; \mathrm{Na}(1)-\mathrm{N}(3)$ 2.408(3); $\mathrm{C}(21)-\mathrm{N}(2)$ 1.275(4); C(32)-N(3) 1.296(4); $\mathrm{Na}(1)-\mathrm{O}(1)$ 2.294(3) N(1)-Na(1)-O(1) 164.62(15); $\mathrm{N}(3)-\mathrm{Na}(1)-\mathrm{N}(2)$ 158.09(12); $\mathrm{N}(2)-\mathrm{C}(21)-\mathrm{C}(10)$ 126.7(3); N(3)-C(32)-C(1) 126.0(3). 4: $\mathrm{K}(1)-$ $\mathrm{N}(1) 2.680(8) ; \mathrm{K}(1)-\mathrm{N}(2)$ 2.747(8); $\mathrm{K}(1)-\mathrm{N}(3)$ 2.762(9); N(2)-C(11)-C(2) 127.1(8); N(3)-C(32)$\mathrm{C}(27) 127.1(9)$.

Crystals of 2-4 suitable for X-ray diffraction studies were grown from concentrated hexane solutions at room temperature. Compounds $\mathbf{2}$ and $\mathbf{3}$ exhibit isostructural monomeric motifs, where the coordination sphere is completed by the tridentate carbazolido ligand and one molecule of THF, with the flanking naphthyls in a syn conformation. In contrast, the solid-state structure for $\mathbf{4}$ reveals an unsolvated bimetallic dimer structure (Fig. 1), which in addition to the analogous $\mathrm{M}-\mathrm{N}$ bond observed for the lighter congeners of the group, the higher hapticity of the ligandmetal binding is supported by an $\eta^{6}$-interaction between the potassium and an additional carbazolido arene ring. The coordination of the metal is completed by an $\eta^{3}$ interaction with one of the adjacent flanking naphthyls. Multi-hapto binding motifs are also found in the potassium complexes $\left[\left(1,8-\mathrm{Xyl}_{2}-3,{ }^{6}-{ }^{t} \mathrm{Bu}_{2} \mathrm{carb}\right) \mathrm{K}(\mathrm{thf})\right]^{12}\left(\eta^{6}, \mathrm{Xyl}=2,6-\right.$ $\left.\mathrm{Me}_{2} \mathrm{C}_{6} \mathrm{H}_{3}\right)$ and $\left[\left(1,8-\mathrm{Ph}_{2}-3,6-\mathrm{Me}_{2} \mathrm{Carb}\right) \mathrm{K}\right]^{20}\left(\eta^{2}\right)$.

An initial assessment of the catalytic activity for dehydrogenation of $\mathrm{Me}_{2} \mathrm{NH} \cdot \mathrm{BH}_{3}$ (Scheme 2) was tested via the reaction of the amine-borane in $\mathrm{C}_{6} \mathrm{D}_{6}$ or THF with 5 mol\% of 2 at room temperature, revealing only minor formation of dehydrogenation products and $\mathrm{LiBH}_{4}$ (Entries 2 and 3, Table 1). Under stoichiometric conditions, no initial conversion at room temperature of $\mathrm{Me}_{2} \mathrm{NH} \cdot \mathrm{BH}_{3}$ was observed, and heating at 70 ${ }^{\circ} \mathrm{C}$ for 67 hours in $\mathrm{C}_{6} \mathrm{D}_{6}$ afforded diaminoborane $7(62 \%)$ as the main product, oligo/polymers (20\%) and the salt $\mathrm{Li}\left[\mathrm{NMe}_{2} \mathrm{BH}_{2} \mathrm{NMe}_{2} \mathrm{BH}_{3}\right](9)(4 \%)$. Noticeably, a ${ }^{7} \mathrm{Li}\left\{{ }^{1} \mathrm{H}\right\}$ NMR spectrum of the resulting reaction mixture exhibited only one resonance at 0.66 
ppm, upfield from the original $3.33 \mathrm{ppm}$ found in $\mathbf{2}$, suggesting a transformation in the lithium species during the reaction.

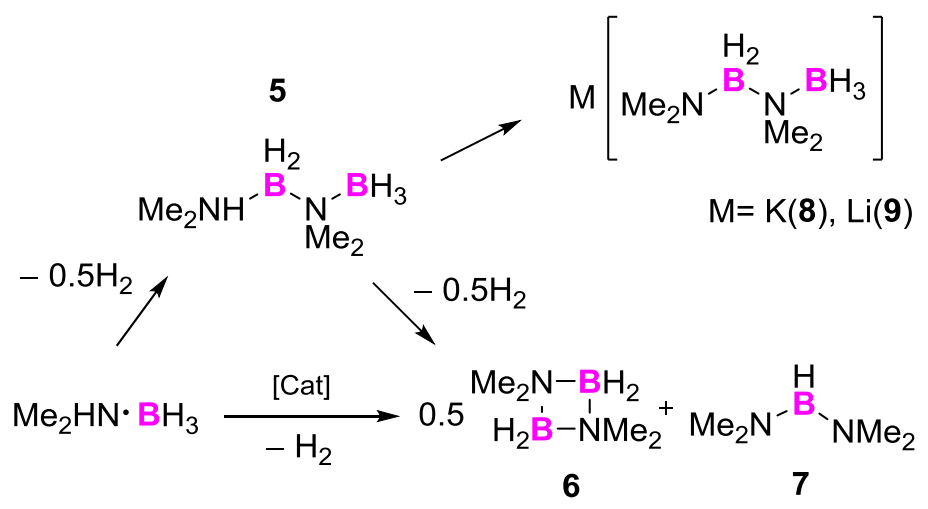

Scheme 2. Dehydrogenation of $\mathrm{Me}_{2} \mathrm{NH} \cdot \mathrm{BH}_{3}$ using 2-4.

When the sodium complex 3 was used as precatalyst in $\mathrm{C}_{6} \mathrm{D}_{6}$ at $70{ }^{\circ} \mathrm{C}$, a colour change from bright orange to colourless was observed and the ${ }^{11} \mathrm{~B}$ NMR spectrum showed the formation of dehydrogenation products; a conversion of $53 \%$ in 1.5 hours (Entry 5, Table 1). Increasing the precatalyst loading to $10 \mathrm{~mol} \%$ leads to higher conversions, 72\% after $1 \mathrm{~h}$ (Entry 6, Table 1). When using THF as a solvent almost no reaction is observed, which further supports an initial exchange/coordination mechanism involving THF and $\mathrm{Me}_{2} \mathrm{NH} \cdot \mathrm{BH}_{3}$ (Entry 7, Table 1). To further understand this, the stoichiometric reaction between 3 and $\mathrm{Me}_{2} \mathrm{NH} \cdot \mathrm{BH}_{3}$ was performed; after 20 hours at $70{ }^{\circ} \mathrm{C}$ most of the amine-borane had decomposed to the diaminoborane [HB(NMe $\left.)_{2}\right]$ (7) (63\%). The formation of a small amounts of $\mathrm{NaBH}_{4}$ were detected at early stages and during the catalytic process. It has been reported that sodium containing salts such as $\mathrm{Na}\left[\mathrm{H}_{3} \mathrm{~B}-\mathrm{NMe}_{2}-\mathrm{BH}_{3}\right]$, decompose in THF solution ${ }^{21,} 22$ forming $\mathrm{NaBH}_{4}$ and the cyclic borazane $\left[\mathrm{Me}_{2} \mathrm{NBH}_{2}\right]_{2}(6)$. No change was observed by ${ }^{11} \mathrm{~B} N M R$ spectroscopy when monitoring the reaction between 3 and $\mathrm{Me}_{2} \mathrm{NH} \cdot \mathrm{BH}_{3}$ at room temperature, but the ${ }^{1} \mathrm{H}$ NMR spectrum displayed a difference in chemical shift from 3, mainly on the pendant flanking groups, which is probably a consequence of the $\mathrm{Me}_{2} \mathrm{NH} \cdot \mathrm{BH}_{3}$ exchanging with the THF on the metal centre. A similar behaviour was observed when the non-active substrate $\mathrm{Me}_{3} \mathrm{~N} \cdot \mathrm{BH}_{3}$ was employed (Fig. S12). The coordination between alkali metals and $\mathrm{Me}_{2} \mathrm{NH} \cdot \mathrm{BH}_{3}$ and/or their dehydrogenation products is well documented, typically relying on hydrogen bond-stabilised interactions with the highly polarised $-\mathrm{NR}_{2}-\mathrm{BH}_{3}$ moieties. ${ }^{7}, 21,23$ DOSY experiments suggest that this species is monomeric in solution (Table S2). Additional experiments evidenced only small changes in the diffusion coefficient during the catalytic process, ruling out the formation of aggregates or dimers in solution. Furthermore, performing the reaction in an open system set-up, with $\mathbf{3}$ as the precatalyst, allowed us to monitor the liberation of $\mathrm{H}_{2}$ occurring in parallel to the formation of the dehydrogenation products. The liberation of $\mathrm{H}_{2}$ observed through this method was consistent with the conversion observed by ${ }^{11} \mathrm{~B}$ NMR spectrum (Fig. S1) and the reaction was scaled up successfully to use $100 \mathrm{mg}$ of $\mathrm{Me}_{2} \mathrm{NH} \cdot \mathrm{BH}_{3}$, where very similar ratios of products were formed in analogous reaction times. 
When the potassium salt 4 (5 mol\%) was employed as the precatalyst in $\mathrm{C}_{6} \mathrm{D}_{6}$ solution, modest conversions were obtained (Entry 10, Table 1). Changing the solvent to THF (using 5 mol\% of 4 ) at $70{ }^{\circ} \mathrm{C}$ yielded limited conversion, with the potassium salt 8 as the main product (Entry 11, Table 1). To further understand the lower catalytic activity of the potassium species, stoichiometric reactions at room temperature were carried out in $\mathrm{C}_{6} \mathrm{D}_{6}\left(2: 1\right.$ ratio of $\left.\mathrm{Me}_{2} \mathrm{NH} \cdot \mathrm{BH}_{3}: 4\right)$; small conversions of $\mathrm{Me}_{2} \mathrm{NH} \cdot \mathrm{BH}_{3}$ to the linear dimer $\mathrm{Me}_{2} \mathrm{NH}-\mathrm{BH}_{2}-\mathrm{NMe}_{2}-\mathrm{BH}_{3}$ (5) were observed (2\%). After an additional 90 hours, low conversion of the starting material was observed (ca. 23\%). From this reaction, crystals suitable for $\mathrm{X}$-ray diffraction were grown from hexane vapour diffusion yielding $\mathrm{K}\left[\mathrm{BH}_{3} \mathrm{NMe}_{2} \mathrm{BH}_{3}\right](\mathbf{8 a})$, probably from the thermal decomposition of 8 (Fig. S19). ${ }^{21}$ When the stoichiometric reactions were performed in THF, even at room temperature, full conversion of $\mathrm{Me}_{2} \mathrm{NH} \cdot \mathrm{BH}_{3}$ was observed, yielding 7 (10\%) and $\mathrm{K}\left[\mathrm{NMe}_{2} \mathrm{BH}_{2} \mathrm{NMe}_{2} \mathrm{BH}_{3}\right](8)(90 \%) .{ }^{7}$ The limited reactivity of 4 in THF is most likely a consequence of the stability of 8 .

Table 1. Dehydrogenation of $\mathrm{Me}_{2} \mathrm{NH} \cdot \mathrm{BH}_{3}$ with 2-4. ${ }^{\text {a) }}$

\begin{tabular}{|c|c|c|c|c|c|c|}
\hline $\begin{array}{l}\text { Entr } \\
\mathrm{y}\end{array}$ & Catalyst (mol\%) & Solvent & $\mathrm{T}\left({ }^{\circ} \mathrm{C}\right)$ & $t(h)$ & Conversion $\left.(\%)^{b}\right)$ & $\begin{array}{l}\text { Product Ratioc) }^{\text {) }} \\
5 / 6 / 7\end{array}$ \\
\hline 1 & - & $\mathrm{C}_{6} \mathrm{D}_{6}$ & 70 & 24 & 0 & - \\
\hline 2 & $2(5)$ & $\mathrm{C}_{6} \mathrm{D}_{6}$ & 70 & 17 & 9 & $<1 / 6 / 2^{\mathrm{d})}$ \\
\hline 3 & $2(5)$ & THF & 70 & 20 & 7 & $1 / 1 / 5^{d)}$ \\
\hline 4 & $2(5)$ & $\begin{array}{l}\text { Pyridin } \\
\text { e }\end{array}$ & 70 & 18 & 99 & $1 / 1 / 97$ \\
\hline 5 & $3(5)$ & $\mathrm{C}_{6} \mathrm{D}_{6}$ & 70 & 1.5 & 53 & $3 / 36 / 14$ \\
\hline 6 & $3(10)$ & $\mathrm{C}_{6} \mathrm{D}_{6}$ & 70 & 1 & 72 & $4 / 47 / 21$ \\
\hline 7 & $3(5)$ & THF & 70 & 4 & 6 & $<1 /<1 / 5$ \\
\hline 8 & $3(5)$ & $\begin{array}{l}\text { Pyridin } \\
\text { e }\end{array}$ & 70 & 1.5 & 23 & $3 / 1 / 19$ \\
\hline 9 & $3(5)$ & $\begin{array}{l}\text { Pyridin } \\
\text { e }\end{array}$ & 70 & 18 & 98 & $3 / 0 / 95$ \\
\hline 10 & $4(5)$ & $\mathrm{C}_{6} \mathrm{D}_{6}$ & 70 & 24 & 24 & $1 / 12 / 11$ \\
\hline 11 & $4(5)$ & THF & 70 & 4 & 4 & $<1 / 1 / 2^{\mathrm{e})}$ \\
\hline 12 & $4(5)$ & $\begin{array}{l}\text { Pyridin } \\
\text { e }\end{array}$ & 70 & 18 & 99 & $<1 /<2 / 98$ \\
\hline 13 & - & $\begin{array}{l}\text { Pyridin } \\
\mathrm{e}\end{array}$ & 70 & 18 & $9^{f)}$ & - \\
\hline
\end{tabular}

a) Reaction conditions: $5.8 \mathrm{mg}, 8.48 \times 10^{-3} \mathrm{mmol}$ of $2-4,0.6 \mathrm{~mL}$ of solvent. Samples were

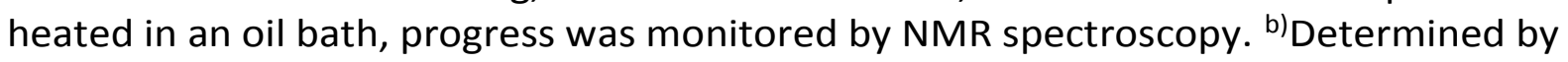

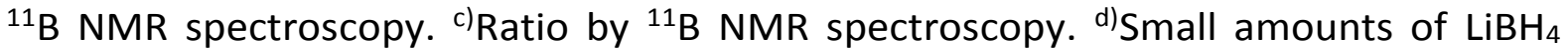
$(<1 \%)$ were detected. ${ }^{\mathrm{e}}$ Selective formation of 8 . ${ }^{\mathrm{f}}$ Formation of $\mathrm{Py} \cdot \mathrm{BH}_{3} .{ }^{24}$

Performing the catalysis in pyridine with 5 mol\% of $2-4$ at $70{ }^{\circ} \mathrm{C}$ for 18 hours, selective formation of 7 was achieved (Entries 4, 9 and 12, Table 1). Reaction in absence of precatalysts confirms that formation of diaminoborane $\mathbf{7}$ does not occur, formation of $\mathrm{Py} \cdot \mathrm{BH}_{3}$ was observed (Entry 13, Table 1 ). ${ }^{24}$ Previous reports highlight the use of polar solvents to promote or limit the interconversion of some of the dehydrogenation products. ${ }^{25}$ This observation, together with our results in pyridine, 
inspired us to employ a series of solvents to investigate the effects of polarity and nucleophilicity on the catalysis (Table 2). MeCN and morpholine showed formation of the corresponding borane adducts $\left(\mathrm{MeCN} \cdot \mathrm{BH}_{3} /\right.$ morpholine $\cdot \mathrm{BH}_{3}$, respectively) and 7 (Entries 4 and 5, Table 2). ${ }^{24}$ When increasing the polarity of the solvent from $\mathrm{C}_{6} \mathrm{D}_{6}$ to $\mathrm{F}_{3} \mathrm{CC}_{6} \mathrm{H}_{5}$ there is a decrease in reaction rate (Entries 1 and 6, Table 2). Selective and quantitative formation of $\mathbf{7}$ was only achieved in pyridine which may be due to the nucleophilicity of the pyridine together with the thermal instability of $\mathrm{Py} \cdot \mathrm{BH}_{3}$ which drives the reaction to 7 (Scheme S1), similar to that reported by Mulvey et. al. ${ }^{24,26}$

It has been postulated that the diminished conversion of the $\mathrm{Me}_{2} \mathrm{NH} \cdot \mathrm{BH}_{3}$ in dehydrogenation reactions occurs due to concomitant formation of insoluble hydrides. ${ }^{8}$ With this in mind, a solution of 3 in $\mathrm{C}_{6} \mathrm{D}_{6}$ was exposed to $\mathrm{H}_{2}$, and a slow but certain decomposition of the precatalyst to the parent carbazole $\mathbf{1}$ was observed (Fig. S13). It seems that upon initial coordination at room temperature and further activation by increase in the temperature, the initial products of dehydrogenation, and more importantly the affiliated liberation of $\mathrm{H}_{2}$, readily convert the Group 1 metal complex into a neutral-ligand/soluble-hydride complex, forming a neutral chelateadduct which can react further. Similar mechanisms have been reported for transitionmetal $^{27}$ and actinide complexes, ${ }^{28}$ in which a hydride-substituted metal is the catalytic species. Although our experiments have shown the potential for the associated $\mathrm{H}_{2}$ to reduce 3 back to the parent ligand, such decomposition has not been observed under the reaction conditions employed during catalysis. Additionally, and looking to understand the nature of the catalytic species at latter stages in the process, we envision that the higher degree of asymmetry observed in the ${ }^{1} \mathrm{H} N M R$ spectra is a consequence of the presence of high number of amine-borane salts as by-products of the reactions. Such salts could work as nucleophiles towards the flanking imines, as shown with the substitution of a butyl chain (Fig. S16). Additionally, some of the byproducts of dehydrogenation are known to reduce unsaturated groups such as imines. ${ }^{22,} 29$

Table 2. Comparison of the dehydrogenation of $\mathrm{Me}_{2} \mathrm{NH} \cdot \mathrm{BH}_{3}$ with 3 in different solvents. ${ }^{\text {a) }}$

\begin{tabular}{|c|c|c|c|c|c|c|}
\hline $\begin{array}{l}\text { Entr } \\
\mathrm{y}\end{array}$ & Catalyst (mol\%) & Solvent & $\mathrm{T}\left({ }^{\circ} \mathrm{C}\right)$ & $t(h)$ & Conv. $(\%)^{b)}$ & $\begin{array}{l}\text { Product Ratiocl } \\
5 / 6 / 7\end{array}$ \\
\hline 1 & $3(5)$ & $\mathrm{C}_{6} \mathrm{D}_{6}$ & 70 & 1.5 & 53 & $3 / 36 / 14$ \\
\hline 2 & $3(5)$ & THF & 70 & 4 & 6 & $<1 /<1 / 5$ \\
\hline 3 & $3(5)$ & Pyridine & 70 & 18 & 98 & 3/0/95 \\
\hline 4 & $3(5)$ & $\mathrm{MeCN}$ & 70 & 18 & 13 & $0 / 0 / 4 / 9^{d)}$ \\
\hline 5 & $3(5)$ & $\begin{array}{l}\text { Morpholin } \\
\text { e }\end{array}$ & 70 & 18 & -e) & - e) \\
\hline 6 & $3(5)$ & $\mathrm{F}_{3} \mathrm{CC}_{6} \mathrm{H}_{5}$ & 70 & 18 & 17 & $3 / 9 / 5$ \\
\hline
\end{tabular}

a) Reaction conditions: $5.8 \mathrm{mg}, 8.48 \times 10^{-3} \mathrm{mmol}$ of $3,0.6 \mathrm{~mL}$ of solvent. Samples were

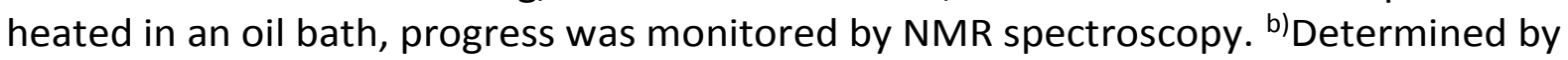
${ }^{11} \mathrm{~B}$ NMR spectroscopy. ${ }^{\mathrm{c})}$ Ratio by ${ }^{11} \mathrm{~B}$ NMR spectroscopy. ${ }^{\text {d) }} \mathrm{MeCN} \cdot \mathrm{BH}_{3}$ ratio. ${ }^{\text {e) }}$ Could not be integrated due to overlapping peaks

Group 1 salts featuring an iminonaphthyl carbazolido NNN pincer ligand are precatalysts in the dehydrogenation of $\mathrm{Me}_{2} \mathrm{NH} \cdot \mathrm{BH}_{3}$, where the cation and solvent 
employed plays a vital role in the outcome of this reaction and the products observed. The reactivity of the three Group 1 salts tested follow a pattern consistent with their relative positions among their group. As such, $\mathbf{2}$ is relatively unreactive, $\mathbf{4}$ readily reacts with $\mathrm{Me}_{2} \mathrm{NH} \cdot \mathrm{BH}_{3}$ forming very stable salts that do not participate in the catalytic cycle, while 3 exhibits an intermediate behaviour. Our observed reactivity differs from that shown by Hill's Group 1 bis(trimethylsilyl)amides; our trend in this reactivity seems to be directly linked to the size of the cation (the smaller/more polarisable, the more reactive), with sodium demonstrating the optimum reactivity for this catalysis. ${ }^{7}$

We gratefully acknowledge the support of the University of Nottingham, the EPSRC, the Leverhulme Trust and CONACYT (Mexican Council for Science and Technology) [CVU 600474]. We also thank the EPSRC UK National Mass Spectrometry Facility at Swansea University and Dr Mick Cooper (University of Nottingham) for mass spectrometry, and Dr Huw Williams (University of Nottingham) for helpful NMR discussions.

\section{Notes and references}

1 R. L. Melen, Chem. Soc. Rev., 2016, 45, 775-788; A. D. Sutton, B. L. Davis, K. X. Bhattacharyya, B. D. Ellis, J. C. Gordon and P. P. Power, Chem. Commun., 2010, 46, 148-149.

2 A. Staubitz, A. P. M. Robertson, M. E. Sloan and I. Manners, Chem. Rev., 2010, 110, 4023-4078; A. Staubitz, A. P. M. Robertson and I. Manners, Chem. Rev., 2010, 110, 4079-4124; S. Bhunya, T. Malakar, G. Ganguly and A. Paul, ACS Catalysis, 2016, 6, 79077934; E. M. Leitao, T. Jurca and I. Manners, Nat. Chem., 2013, 5, 817-829.

3 Y. Jiang, O. Blacque, T. Fox, C. M. Frech and H. Berke, Organometallics, 2009, 28, 54935504; E. M. Leitao, N. E. Stubbs, A. P. Robertson, H. Helten, R. J. Cox, G. C. Lloyd-Jones and I. Manners, J. Am. Chem. Soc., 2012, 134, 16805-16816.

4 S. Frueh, R. Kellett, C. Mallery, T. Molter, W. S. Willis, C. King'ondu and S. L. Suib, Inorg. Chem., 2011, 50, 783-792; H. C. Johnson, E. M. Leitao, G. R. Whittell, I. Manners, G. C. Lloyd-Jones and A. S. Weller, J. Am. Chem. Soc., 2014, 136, 9078-9093; J. C. Koepke, J. D. Wood, Y. Chen, S. W. Schmucker, X. Liu, N. N. Chang, L. Nienhaus, J. W. Do, E. A. Carrion, J. Hewaparakrama, A. Rangarajan, I. Datye, R. Mehta, R. T. Haasch, M. Gruebele, G. S. Girolami, E. Pop and J. W. Lyding, Chem. Mater., 2016, 28, 4169-4179.

5 J. Spielmann, M. Bolte and S. Harder, Chem. Commun., 2009, 6934-6936; D. J. Liptrot, M. S. Hill, M. F. Mahon and D. J. MacDougall, Chem. Eur. J., 2010, 16, 8508-8515; J. Spielmann, D. F.-J. Piesik and S. Harder, Chem. Eur. J., 2010, 16, 8307-8318; Y. S. Chua, H. Wu, W. Zhou, T. J. Udovic, G. Wu, Z. Xiong, M. W. Wong and P. Chen, Inorg. Chem., 2012, 51, 1599-1603.

6 H. J. Cowley, M. S. Holt, R. L. Melen, J. M. Rawson and D. S. Wright, Chem. Commun., 2011, 47, 2682-2684; M. M. Hansmann, R. L. Melen and D. S. Wright, Chem. Sci., 2011, 2, 1554-1559; R. J. Less, H. R. Simmonds, S. B. Dane and D. S. Wright, Dalton Trans, 2013, 42, 6337-6343; J. D. Erickson, T. Y. Lai, D. J. Liptrot, M. M. Olmstead and P. P. Power, Chem. Commun., 2016, 52, 13656-13659; Z. Mo, A. Rit, J. Campos, E. L. Kolychev and S. Aldridge, J. Am. Chem. Soc., 2016, 138, 3306-3309.

7 P. Bellham, M. S. Hill and G. Kociok-Kohn, Dalton Trans., 2015, 44, 12078-12081.

8 R. McLellan, A. R. Kennedy, S. A. Orr, S. D. Robertson and R. E. Mulvey, Angew. Chem. Int. Ed., 2017, 56, 1036-1041. 
9 A. Harinath, S. Anga and T. K. Panda, RSC Adv., 2016, 6, 35648-35653; C. Cheng, B. G. Kim, D. Guironnet, M. Brookhart, C. Guan, D. Y. Wang, K. Krogh-Jespersen and A. S. Goldman, J. Am. Chem. Soc., 2014, 136, 6672-6683.

10 A. Kumar, T. M. Bhatti and A. S. Goldman, Chem. Rev., 2017, 117, 12357-12384.

11 A. J. Blake, W. Lewis, J. McMaster, R. S. Moorhouse, G. J. Moxey and D. L. Kays, Dalton Trans., 2011, 40, 1641-1645; R. S. Moorhouse, G. J. Moxey, F. Ortu, T. J. Reade, W. Lewis, A. J. Blake and D. L. Kays, Inorg. Chem., 2013, 52, 2678-2683.

12 F. Ortu, G. J. Moxey, A. J. Blake, W. Lewis and D. L. Kays, Chem. Eur. J., 2015, 21, 69496956.

13 J. A. Gaunt, V. C. Gibson, A. Haynes, S. K. Spitzmesser, A. J. P. White and D. J. Williams, Organometallics, 2004, 1015-1023.

14 M. Inoue, T. Suzuki and M. Nakada, J. Am. Chem. Soc., 2003, 1140-1141.

15T. Niwa and M. Nakada, J. Am. Chem. Soc., 2012, 134, 13538-13541.

16D. Bezier, C. Guan, K. Krogh-Jespersen, A. S. Goldman and M. Brookhart, Chem. Sci., 2016, 7, 2579-2586.

17V. C. Gibson, S. K. Spitzmesser, A. J. P. White and D. J. Williams, Dalton Trans., 2003, 2718-2727; J. M. Barbe, B. Habermeyer, T. Khoury, C. P. Gros, P. Richard, P. Chen and K. M. Kadish, Inorg. Chem., 2010, 49, 8929-8940.

18 H. B. Mansaray, M. Kelly, D. Vidovic and S. Aldridge, Chem. Eur. J., 2011, 17, 53815386.

19 K. Gregory, M. Bremer, P. v. R. Schleyer, P. A. A. Klusener and L. Brandsma, Angew. Chem. Int. Ed., 1989, 1224-1226; H. Esbak and U. Behrens, Z. Anorg. Allg. Chem., 2005, 631, 1581-1587.

20 N. D. Coombs, A. Stasch, A. Cowley, A. L. Thompson and S. Aldridge, Dalton Trans., 2008, 332-337.

21 H. Nöth and S. Thomas, Eur. J. Inorg. Chem., 1999, 1373-1379.

22 X. Chen, J.-C. Zhao and S. G. Shore, J. Am. Chem. Soc., 2010, 10658-10659.

23 R. J. Less, R. Garcia-Rodriguez, H. R. Simmonds, L. K. Allen, A. D. Bond and D. S. Wright, Chem. Commun., 2016, 52, 3650-3652.

24 P. V. Ramachandran and A. S. Kulkarni, RSC Adv., 2014, 4, 26207-26210.

25 C. J. Stevens, R. Dallanegra, A. B. Chaplin, A. S. Weller, S. A. Macgregor, B. Ward, D. McKay, G. Alcaraz and S. Sabo-Etienne, Chem. Eur. J., 2011, 17, 3011-3020; A. P. Robertson, R. Suter, L. Chabanne, G. R. Whittell and I. Manners, Inorg. Chem., 2011, 50, 12680-12691.

26R. McLellan, A. R. Kennedy, R. E. Mulvey, S. A. Orr and S. D. Robertson, Chem. Eur. J., 2017, 23, 16853-16861.

27 A. Rossin and M. Peruzzini, Chem. Rev., 2016, 116, 8848-8872; E. M. Titova, E. S. Osipova, A. A. Pavlov, O. A. Filippov, S. V. Safronov, E. S. Shubina and N. V. Belkova, ACS Catalysis, 2017, 7, 2325-2333.

28 K. A. Erickson and J. L. Kiplinger, ACS Catalysis, 2017, 7, 4276-4280.

29 G. B. Fisher, J. C. Fuller, J. Harrison, S. G. Alvarez, E. R. Burkhardt, C. T. Goralski and B. Singaram, J. Org. Chem., 1994, 6378-6385; B. T. Cho and S. K. Kang, Tetrahedron, 2005, 61, 5725-5734. 